\title{
SOROPREVALÊNCIA E FATORES DE RISCO PARA Babesia bovis EM REBANHOS LEITEIROS NA REGIÃO SUL DE MINAS GERAIS ${ }^{1}$
}

\author{
Seroprevalence and risk factors for Babesia bovis in dairy cattle \\ from region southern Minas Gerais state, Brazil ${ }^{1}$
}

\author{
Antônio Marcos Guimarães ${ }^{2}$, André Henrique Oliveira Carvalho ${ }^{3}$, Débora Oliveira Daher, \\ Christiane Maria Barcellos Magalhães da Rocha², Christian Hirsch ${ }^{2}$
}

\begin{abstract}
RESUMO
Conduziu-se este trabalho, com o objetivo de determinar a prevalência e os fatores de risco associados à soropositividade para Babesia bovis em 556 bovinos leiteiros procedentes de dez propriedades localizadas no sul de Minas Gerais, as quais foram divididas em dois grupos de acordo com a produção média diária de leite: Alta Produção (AP) $>2.0001$ de leite/dia, e Baixa Produção (BP) $\leq 500$ 1 de leite/dia. Os soros foram submetidos à reação de imunofluorescência indireta (RIFI) para pesquisa de anticorpos anti-B. bovis e considerados positivos na diluição de 1:320. A análise estatística foi realizada no programa SPSS 12.0 for Windows e se buscou determinar a associação entre níveis de positividade para B. bovis nos rebanhos e os fatores de risco por meio do Teste Exato de Fischer. Para testar a diferença das médias de soropositividade, foi utilizado o teste T Student e em todos os cálculos considerou-se o grau de significância de $95 \%$. A prevalência média global de bovinos infectados por B. bovis foi de 94,1\% (523/556). Não houve diferença significativa na frequência média de anticorpos anti-B. bovis entre as propriedades leiteiras dos grupos de AP (95,97\%) e BP $(92,22 \%)$; e o mesmo resultado foi observado entre os animais jovens e adultos de ambos os grupos. Não foi observada associação significativa entre os fatores de risco avaliados e a taxa de bovinos positivos para B. bovis. A alta prevalência de rebanhos leiteiros soropositivos permite caracterizar, epidemiologicamente, a microrregião de Lavras, sul de Minas Gerais, como área de elevada estabilidade endêmica para B. bovis.
\end{abstract}

Termos para indexação: Babesiose, bovinos leiteiros, reação de imunofluorescência indireta (RIFI), tristeza parasitária bovina.

\section{ABSTRACT}

The objective of this study was to determine the prevalence and risk factors associated with Babesia bovis infection in 556 dairy cattle from ten properties located in southern Minas Gerais State, Brazil. The herds were divided into two groups according to average daily milk production (liters): I- High Production (HP), >2,000 L milk/day; and II- Low Production (LP), $\leq 500 \mathrm{~L}$ milk/day. The serum samples were submitted to the indirect fluorescent antibody test (IFAT) for antibodies anti-B. bovis and they were considered positive at a dilution of 1:320. The statistical analysis was performed using SPSS 12.0 for Windows. It was stated the association between positivity levels for $B$. bovis in dairy herds and the risk factors (farm size, production system, breed and feeding system) by Fisher exact test. The average prevalence of cattle with $B$. bovis infection was $94.06 \%(523 / 556)$. There was no significant difference ( $\mathrm{p}>0.05)$ in the average frequency of antibodies anti-B. bovis between the groups of HP (95.97\%) and LP (92.22\%), and similar results were observed between young or adult cattle for both groups. The association between risk factors and seroprevalence of $B$. bovis has not been previously reported $(\mathrm{p}>0.05)$. The high prevalence of seropositive dairy herds allows to characterize epidemiologically the microregion of Lavras, south of Minas Gerais State, an area of enzootic stability to B. bovis.

Index terms: Babesiosis, dairy cattle, indirect fluorescent antibody test (IFAT), tick-borne diseases.

(Recebido em 8 de abril de 2009 e aprovado em 30 de setembro de 2010)

\section{INTRODUÇÃO}

A babesiose bovina, que no Brasil tem como agentes etiológicos protozoários do filo Apicomplexa, Babesia bovis (STARCOVICI, 1893) e B. bigemina (SMITH; KILBORNE, 1893), é uma doença parasitária responsável por expressivas perdas econômicas em todo o mundo (KUTTLER, 1988). Nas Américas, a distribuição geográfica de bovinos infectados por B. bovis e/ou B. bigemina segue a dispersão do carrapato vetor Rhipicephalus (Boophilus) microplus (GUGLIELMONE, 1995), espécie comum em áreas tropicais e subtropicais do mundo, e amplamente distribuída na África, Austrália e Américas do Sul e Central (FOIL et al., 2004; VILORIA; SALCEDO, 2004).

No Brasil, a infecção por B. bovis é comum nos rebanhos bovinos em diversas regiões do país, com taxas que variam entre $80 \%$ a 100\% (ARAÚJO et al., 1997). Mas, segundo esses mesmos autores, em razão do seu vasto

${ }^{1}$ Projeto financiado pela Fundação de Amparo à Pesquisa do Estado de Minas Gerais (FAPEMIG)

²Universidade Federal de Lavras/UFLA - Departamento de Medicina Veterinária/DMV - Cx. P. 3037 - 37200-000 - Lavras, MG - amg@ufla.br

3Universidade Federal de Lavras/UFLA - Lavras, MG 
território, é comum a presença de regiões classificadas como de estabilidade ou instabilidade endêmica. Nas áreas de estabilidade endêmica existe um equilíbrio entre imunidade e doença, sendo que $75 \%$ dos animais com idade acima de nove meses são portadores de hemoparasitos. Já, nas áreas de instabilidade endêmica, a porcentagem de animais acima de nove meses infectados está entre $20 \%$ a $75 \%$, sendo esses níveis detectados por meio de testes sorológicos.

Condições climáticas tropicais e subtropicais favorecem o desenvolvimento do carrapato $R$. (B.) microplus e conferem à babesiose características de estabilidade endêmica. Nos locais onde o clima interfere no desenvolvimento do $R$. (B.) microplus, tornando, desse modo, a transmissão irregular, situações de instabilidade endêmica são criadas, ocorrendo surtos de babesiose (BARCI et al., 1995).

Para se determinar o perfil de estabilidade ou instabilidade de uma região, devem-se avaliar diversos fatores, como os inerentes ao animal (raça, idade), e variações climáticas, estresse, manejo e tipo de pastagens. As raças Bos taurus são mais sensíveis aos carrapatos e assim, às hemoparasitoses, enquanto o gado zebu Bos indicus é, naturalmente, mais resistente; e os bovinos adultos são mais suscetíveis que os jovens (JONSSON et al., 2008).

Os fatores climáticos podem ter importância na epidemiologia da babesiose, influenciando a população de carrapatos ou a transmissão do protozoário. Do mesmo modo, as práticas de manejo instituídas no sistema de criação de vacas como o uso de instalações do tipo "free stall" e determinados tipos de bezerreiros onde os bezerros são mantidos permanentemente estabulados, sendo que, em ambos os sistemas, os bovinos são mantidos praticamente livres de carrapatos.

Vários pesquisadores têm chamado a atenção para a importância de se conhecer a situação epidemiológica de uma região por meio de estudos regionais, ou seja, indicando se há estabilidade ou instabilidade endêmica para determinada hemoparasitose e, consequentemente, mensurar a probabilidade de ocorrência de surtos de importância econômica da doença e a necessidade ou não da adoção de medidas preventivas.

A região sul de Minas Gerais se destaca como uma das principais bacias leiteiras do país, abastecendo grandes centros como São Paulo, além de fornecer matéria-prima para as indústrias de laticínios localizadas no próprio Estado. Em razão da importância da babesiose bovina, associada à escassez de informações sobre a epidemiologia dessa doença na região Sul, do estado de Minas Gerais, o principal objetivo, neste estudo foi determinar a prevalência e os fatores de risco associados à infecção por B. bovis em rebanhos leiteiros da microrregião de Lavras, uma das principais regiões produtoras de leite do Estado.

\section{MATERIAL E MÉTODOS}

Caracterização da área de estudo. A microrregião de Lavras se caracteriza como um importante pólo de produção de leite no sul de Minas Gerais, com um total de 45.000 vacas em ordenha e uma produção média de 112.366.000 litros de leite por ano (INSTITUTO BRASILEIRO DE GEOGRAFIA E ESTATÍSTICA - IBGE, 2004). Essa microrregião possui um clima tipo Cwa, temperado de altitude, segundo a classificação de KOPPEN, com duas estações bem definidas durante o ano (ANTUNES, 1986). A estação chuvosa, geralmente começa em outubro e se estende até março, e o período seco compreendido entre os meses de abril a setembro.

Amostras de soro. Neste estudo foram utilizadas 556 amostras de um banco de soros bovino, procedentes de dez fazendas produtoras de leite tipo $\mathrm{B}$ ou $\mathrm{C}$, coletadas no período de janeiro a março de 2004, e que foram visitadas uma única vez cada. Para caracterizar as propriedades, durante as visitas foram aplicadas entrevistas aos produtores levantando as principais características das fazendas, que serviram de variáveis independentes para este estudo.

As propriedades foram divididas em dois grupos de acordo com a produção diária de leite: Alta Produção (AP) - cinco fazendas com uma produção >2.000 litros de leite/dia; e Baixa Produção (BP) - cinco fazendas com uma produção $\leq 500$ litros de leite/dia. Os bovinos de ambos os grupos foram subdivididos em duas categorias, de acordo com a faixa etária: Jovem $(\mathrm{J})>4$ meses a $\leq 24$ meses de vida (bezerros e novilhas) e Adulto (A) $>24$ meses de idade (vacas).

Sorologia. A reação de imunofluorescência indireta (RIFI) foi realizada no Laboratório de Parasitologia do Departamento de Medicina Veterinária da Universidade Federal de Lavras (DMV/UFLA), de acordo com o Instituto Interamericano de Cooperacion para la Agricultura - IICA (1987), utilizando como antígeno lâminas de B. bovis produzidas no próprio laboratório. A RIFI, em razão da sua alta sensibilidade e especificidade, tem sido o teste sorológico de referência para a pesquisa de anticorpos anti-B. bovis. Foi considerado positivo (cut off) o soro que apresentou título na diluição 1:320 (SANTOS et al., 2001). Análise estatística. A análise estatística foi realizada no programa SPSS 12.0 for Windows, e se buscou determinar a associação entre níveis de positividade para $B$. bovis nos rebanhos e os fatores de risco (tamanho da propriedade, sistema de criação, grupo racial, tipo de 
ordenha e alimentação dos animais), por meio do Teste Exato de Fischer. Para testar a diferença de médias de soropositividade dentro e entre os rebanhos bovinos foi utilizado o Teste T Student e em todos os cálculos considerou-se o grau de significância de $95 \%$.

\section{RESULTADOS E DISCUSSÃO}

Soroprevalência: A analise das 556 amostras de soros de bovinos leiteiros da microrregião de Lavras submetidos à reação de imunofluorescência indireta (RIFI), demonstrou que $523(94,1 \%)$ foram positivas para B. bovis (Tabela 1). O grupo de alta produção leiteira (AP) não apresentou diferença significativa na taxa média de soropositividade para B. bovis se comparado ao grupo de baixa produção (BP). Também não houve diferença significativa entre os animais jovens (J) ou adultos (A) no grupo de AP, fato que também se repetiu no grupo de BP, conforme determinado nas Tabelas 2, 3, 4 e 5, respectivamente.

Independente da média diária de produção leiteira (AP ou BP) ou da faixa etária dos bovinos (J ou A), 90\% das fazendas (9/10) apresentaram frequências médias de animais soropositivos acima de $75 \%$ para $B$. bovis (mín. $=82,1 \%$ e max. $=100 \%$ ), que, de acordo com os conceitos epidemiológicos propostos por Mahoney e Ross (1972), caracteriza a microrregião de Lavras como área de elevada estabilidade endêmica para esse hemoparasita. Neste estudo, apenas uma propriedade (1/10), com $68,7 \%$ dos bovinos soropositivos, apresentou uma frequência de anticorpos anti-B. bovis abaixo de $75 \%$, caracterizando uma situação de instabilidade endêmica (MAHONEY; ROSS, 1972). Assim, a probabilidade de surtos de $B$. bovis em rebanhos leiteiros dessa microrregião é baixa, porém constitui-se em área de risco no caso de introdução de animais suscetíveis procedentes de regiões livres ou de instabilidade endêmica, que necessitariam primeiramente ser submetidos a um processo de imunização para este hemoparasita (GUGLIELMONE, 1995).

Embora apresentando pequenas variações na taxa de bovinos soropositivos para B. bovis em relação a outros estudos, em razão das características epidemiológicas próprias de cada região, a situação de estabilidade endêmica para $B$. bovis determinada no presente trabalho é similar à relatada em pesquisas realizadas em Minas Gerais (PATARROYO et al., 1987) e nos estados de São Paulo (BARCI et al., 1995), Bahia (ARAÚJO et al., 1997), Rio de Janeiro (SOARES et al., 2000), Mato Grosso do Sul (MADRUGA et al., 2000) e Goiás (SANTOS et al., 2001).

Não houve diferença significativa na frequência de anticorpos anti-B. bovis entre os animais jovens ( $>4$ a $<24$ meses de idade) e adultos ( $>24$ meses de idade), independente do nível de produção de leite (alto ou baixo). Possivelmente, o sistema de manejo dos animais jovens, adotado em ambos os grupos (AP ou BP), permitiu uma boa exposição ao carrapato vetor $R$. (B.) microplus nas primeiras semanas de vida e, consequentemente, uma elevada taxa de inoculação de B. bovis, comportamento que se estendeu durante a fase adulta. Estudo desenvolvido no estado de Minas Gerais demonstrou que o $R$. (B.) microplus, sob condições naturais, apresenta quatro gerações por ano, favorecendo a infestação dos animais durante os 12 meses, com picos no período chuvoso (LIMA et al., 2000). Em áreas endêmicas a primoinfecção para Babesia ocorre nas primeiras semanas de vida (SANTANA et al., 2008).

Fatores de risco: Os parâmetros descritivos e a caracterização das propriedades dos grupos de alta produção (AP) ou baixa produção (BP) leiteira estão representados nas Tabelas 6 e 7, respectivamente. Nenhum dos fatores de risco analisados (o tamanho da propriedade, o sistema de criação, o grupo racial e o tipo de alimentação dos animais) apresentou associação significativa com a taxa de anticorpos anti-B. bovis, tanto para os rebanhos de $\mathrm{AP}$ (>2.000 l de leite/dia) como para aqueles de $\mathrm{BP}(<500$ 1 de leite/dia) leiteira, provavelmente em função da elevada soroprevalência média observada em ambos os grupos, que ficou acima de $90 \%$.

Embora com a maioria dos parâmetros descritivos bem distintos, as propriedades leiteiras dos grupos de AP ou BP

Tabela 1 - Frequência média global (\%) de bovinos soropositivos para Babesia bovis em propriedades leiteiras dos grupos de alta produção (AP) e baixa produção (BP) leiteira, de acordo com a faixa etária, sul de Minas Gerais, 2004.

\begin{tabular}{ccccccccc}
\hline Idade & \multicolumn{2}{c}{ Grupo AP $(>2.000$ 1/dia $)$} & \multicolumn{2}{c}{ Grupo BP $(<5001 /$ dia $)$} & \multicolumn{3}{c}{ Total } \\
\cline { 2 - 9 }$($ meses $)$ & $\mathrm{n}$ & Positivo & $\%$ & $\mathrm{~N}$ & Positivo & $\%$ & Positivo & $\%$ \\
\hline$>4 \mathrm{a}<24$ & 147 & 143 & $97,3^{\mathrm{a}}$ & 124 & 116 & $93,5^{\mathrm{a}}$ & 259 & 95,6 \\
$>24$ & 126 & 119 & $94,4^{\mathrm{a}}$ & 159 & 145 & $91,2^{\mathrm{a}}$ & 264 & 92,6 \\
Total & 273 & 262 & $96,0^{\mathrm{a}}$ & 283 & 261 & $92,2^{\mathrm{a}}$ & 523 & 94,1 \\
\hline
\end{tabular}

Valores seguidos por letras diferentes na mesma linha diferem entre si pelo teste de T Student $(\mathrm{p}<0,05)$. 
Tabela 2 - Frequência (\%) de animais jovens ( $>4$ a $<24$ meses de idade) soropositivos para Babesia bovis nas fazendas de alta produção leiteira (>2.000 1/dia) estudadas, sul de Minas Gerais, 2004.

\begin{tabular}{cccc}
\hline Fazenda & Tipo de leite & $\mathrm{N}^{\mathrm{o}}$ de animais testados & $\mathrm{N}^{\mathrm{o}}$ de animais positivos $(\%)$ \\
\hline 1 & $\mathrm{~B}$ & 32 & $32(100,0)$ \\
2 & $\mathrm{~B}$ & 32 & $31(96,8)$ \\
3 & $\mathrm{~B}$ & 26 & $24(92,3)$ \\
4 & $\mathrm{~B}$ & 28 & $28(100,0)$ \\
5 & $\mathrm{~B}$ & 29 & $28(96,5)$ \\
\hline & & 147 & $143(97,3)$ \\
\hline
\end{tabular}

Tabela 3 - Frequência (\%) de animais adultos (>24 meses de idade) soropositivos para Babesia bovis nas fazendas de alta produção leiteira (>2.000 1/dia) estudadas, sul de Minas Gerais, 2004.

\begin{tabular}{|c|c|c|c|}
\hline Fazenda & Tipo de leite & № de animais testados & № de animais positivos (\%) \\
\hline 1 & B & 32 & $31(96,9)$ \\
\hline 2 & B & 32 & $32(100,0)$ \\
\hline 4 & $\mathrm{~B}$ & 31 & $29(93,5)$ \\
\hline 5 & $\mathrm{~B}$ & 31 & $27(87,1)$ \\
\hline \multicolumn{2}{|c|}{ Total } & 126 & $119(94,4)$ \\
\hline
\end{tabular}

Tabela 4 - Frequência (\%) de animais jovens ( $>4$ a $<24$ meses de idade) soropositivos para Babesia bovis nas fazendas de baixa produção leiteira (<500 1/dia) estudadas, sul de Minas Gerais, 2004.

\begin{tabular}{cccc}
\hline Fazenda & Tipo de leite & $\mathrm{N}^{-}$de animais testados & $\mathrm{N}^{\mathrm{o}}$ de animais positivos $(\%)$ \\
\hline 6 & $\mathrm{C}$ & 28 & $23(82,1)$ \\
7 & $\mathrm{~B}$ & 20 & $18(90,0)$ \\
8 & $\mathrm{C}$ & 29 & $28(96,5)$ \\
9 & $\mathrm{C}$ & 29 & $29(100,0)$ \\
10 & $\mathrm{~B}$ & 18 & $18(100,0)$ \\
\hline & & 124 & $116(93,5)$ \\
\hline
\end{tabular}

Tabela 5 - Frequência (\%) de animais adultos (>24 meses de idade) soropositivos para Babesia bovis nas fazendas de baixa produção leiteira (<500 1/dia) estudadas, sul de Minas Gerais, 2004.

\begin{tabular}{|c|c|c|c|}
\hline Fazenda & Tipo de leite & № de animais testados & № de animais positivos (\%) \\
\hline 6 & $\mathrm{C}$ & 32 & $22(68,7)$ \\
\hline 7 & $\mathrm{~B}$ & 32 & $32(100,0)$ \\
\hline 8 & $\mathrm{C}$ & 31 & $27(87,1)$ \\
\hline 9 & $\mathrm{C}$ & 32 & $32(100,0)$ \\
\hline 10 & $\mathrm{~B}$ & 32 & $32(100,0)$ \\
\hline \multicolumn{2}{|c|}{ Total } & 159 & $145(91,2)$ \\
\hline
\end{tabular}


Tabela 6 - Parâmetros descritivos de propriedades leiteiras dos grupos AP (>2.000 1 de leite/dia) e BP (<500 1 de leite/ dia), sul de Minas Gerais, 2004.

\begin{tabular}{ccc}
\hline Características & \multicolumn{2}{c}{ Média \pm dp (Mínimo - Máximo) } \\
\cline { 2 - 3 } Número total de bovinos & Grupo AP $(\mathrm{n}=5)$ & Grupo BP $(\mathrm{n}=5)$ \\
\hline Área total da propriedade $(h a)$ & $380,0^{\mathrm{a}} \pm 149,3$ & $89,6^{\mathrm{b}} \pm 25,2$ \\
& $(200-600)$ & $(60-131)$ \\
Densidade animal (cabeça/ha) & $361,0^{\mathrm{a}} \pm 205,6$ & $\left(13,6^{\mathrm{b}} \pm 96,8\right.$ \\
& $(180-700)$ & $(30-300)$ \\
& $1,17^{\mathrm{a}} \pm 0,3$ & $(0,4-2,9)$ \\
Número médio de vacas em lactação & $(0,9-1,6)$ & $29,0^{\mathrm{b}} \pm 4,3$ \\
& $150,4^{\mathrm{a}} \pm 31,3$ & $(24-36)$ \\
Produção total média de leite por fazenda/dia (litros) & $(112-205)$ & $397,2^{\mathrm{b}} \pm 101,5$ \\
& $2.560,0^{\mathrm{a}} \pm 621,6$ & $(250-500)$ \\
Produção média de leite por vaca/dia (litros) & $(2.200-3.800)$ & $13,8^{\mathrm{b}} \pm 3,5$ \\
& $17,1^{\mathrm{a}} \pm 2,3$ & $(8,3-18,3)$ \\
Intervalo médio entre banhos carrapaticidas (dias) & $(13,7-20,5)$ & $36,2^{\mathrm{a}} \pm 13,9$ \\
& $32^{\mathrm{a}} \pm 14,7$ & $(25-60)$
\end{tabular}

Valores seguidos por letras diferentes na mesma linha diferem entre si pelo teste de T Student $(\mathrm{p}<0,05)$.

Tabela 7 - Caracterização das propriedades leiteiras dos grupos A (>2.000 l de leite/dia) e B (<500 1 de leite/dia), sul de Minas Gerais, 2004.

\begin{tabular}{|c|c|c|}
\hline \multirow[b]{2}{*}{ Características } & \multicolumn{2}{|c|}{ Frequência (\%) } \\
\hline & Grupo A $(n=5)$ & Grupo B $(n=5)$ \\
\hline \multicolumn{3}{|l|}{ Tipo de leite produzido } \\
\hline Tipo B & $100(5 / 5)$ & $40(2 / 5)$ \\
\hline Tipo C & - & $60(3 / 5)$ \\
\hline \multicolumn{3}{|l|}{ Tipo de ordenha } \\
\hline Mecânica & $100(5 / 5)$ & $80(4 / 5)$ \\
\hline Manual & - & $20(1 / 5)$ \\
\hline \multicolumn{3}{|l|}{ Composição racial do rebanho } \\
\hline Puro & $40(2 / 5)$ & $60(3 / 5)$ \\
\hline Mestiço & - & $40(2 / 5)$ \\
\hline Ambos & $60(3 / 5)$ & - \\
\hline \multicolumn{3}{|l|}{ Sistema de criação dos animais } \\
\hline Intensivo & $20(1 / 5)$ & $20(1 / 5)$ \\
\hline Semi-intensivo & $80(4 / 5)$ & $80(4 / 5)$ \\
\hline \multicolumn{3}{|l|}{ Tipo de alimentação do rebanho } \\
\hline Pasto + concentrado & $60(3 / 5)$ & $100(5 / 5)$ \\
\hline Confinado (concentrado + volumoso no cocho) & $40(2 / 5)$ & - \\
\hline \multicolumn{3}{|l|}{ Modo de reposição dos animais de descarte } \\
\hline Com animais do próprio rebanho & $100(5 / 5)$ & $80(4 / 5)$ \\
\hline Compra de novos animais & - & - \\
\hline Ambos & - & $20(1 / 5)$ \\
\hline \multicolumn{3}{|l|}{ Controle de carrapatos } \\
\hline Sim & $100(5 / 5)$ & $100(5 / 5)$ \\
\hline Não & - & - \\
\hline \multicolumn{3}{|c|}{ Possui animais que foram submetidos à pré- imunização para TPB* } \\
\hline $\operatorname{Sim}$ & - & - \\
\hline Não & $100(5 / 5)$ & $100(5 / 5)$ \\
\hline
\end{tabular}

${ }^{*} \mathrm{TPB}=$ Tristeza Parasitiria Bovina.

Ciênc. agrotec., Lavras, v. 35, n. 4, p. 826-832, jul./ago., 2011 
não apresentaram diferença significativa nos itens relativos à densidade animal e ao intervalo entre banhos carrapaticidas (Tabela 6). A densidade animal, em ambos os grupos, foi elevada (>1 cabeça/ha), favorecendo a infestação dos bovinos por larvas de $R$. (B.) microplus e a inoculação de $B$. bovis (Guglielmone, 1995). Esse mesmo raciocínio pode ser aplicado ao intervalo médio entre banhos carrapaticidas, que ficou acima de 30 dias em ambos os grupos, não interferindo na exposição ao carrapato vetor $R$. (B.) microplus e, consequentemente, na taxa de inoculação de $B$. bovis. Resultado distinto foi relatado por Solorio-Rivera et al. (1999), no México, que avaliando o efeito das práticas de manejo sobre a prevalência de bovinos (399 Bos indicus de 1-2 anos de idade) soropositivos para B. bovis, observaram a densidade animal $(<1$ cabeça/ha) e intervalo de banho carrapaticida $(>60$ dias) como fatores de risco associados $(\mathrm{p}<0,05)$ com a taxa de bovinos reagentes. Entretanto, nesse mesmo estudo, fatores de risco como tipo de fazenda, sistema de produção, tamanho do rebanho e área da fazenda, entre outros avaliados, não apresentaram associação ( $\mathrm{p}>0,05)$ com a prevalência de bovinos soropositivos para $B$. bovis.

As variáveis descritas das propriedades de ambos os grupos (Tabela 7), embora com pequenas diferenças, permitem inferir que os rebanhos leiteiros apresentam sistema de manejo muito similar, favorecendo a infestação pelo carrapato vetor $R$. (B.) microplus. A composição racial dos rebanhos (holandês ou holandês+zebu), o predomínio do sistema de criação semi-intensivo e da alimentação a pasto, associado à forma de reposição dos animais que são descartados, geralmente decorrentes da baixa produção de leite ou problemas reprodutivos, não interferiram na exposição dos bovinos ao carrapato vetor $R$. (B.) microplus, e permitiram que os animais tivessem uma alta taxa de inoculação e, consequentemente, propiciando uma situação de elevada estabilidade endêmica para B. bovis.

\section{CONCLUSÃO}

Os resultados obtidos neste estudo indicam que, as propriedades leiteiras da microrregião de Lavras, região Sul do estado de Minas Gerais, se caracterizam epidemiologicamente como sendo de alta estabilidade endêmica para $B$. bovis, com baixo risco de ocorrência de surtos em bovinos oriundos dessa região.

\section{AGRADECIMENTOS}

Os autores agradecem aos proprietários e funcionários das fazendas leiteiras pela oportunidade de desenvolvimento deste estudo e à FAPEMIG (Fundação de Amparo à Pesquisa do Estado de Minas Gerais) pelo suporte financeiro.

\section{REFERÊNCIAS BIBLIOGRÁFICAS}

ANTUNES, F. Caracterização climática do Estado de Minas Gerais. Informe Agropecuário, Belo Horizonte, v.12, n.138, p.9-13, 1986.

ARAÚJO, F.R. et al. Levantamento sorológico de Babesia bovis e Babesia bigemina no Estado da Bahia pela imunofluorescência indireta e teste de conglutinação rápida. Revista Brasileira de

Parasitologia Veterinária, São Paulo, v.6, n.2, p.111-115, 1997.

BARCI, L.A.G. et al. Epidemiologia da babesiose bovina no Estado de São Paulo: I., estudo em rebanhos produtores de leite tipo B do município de Pindamonhangaba, Vale do Paraíba. Revista Brasileira de Parasitologia Veterinária, São Paulo, v.3, n.2, p.7982, 1995.

FOIL, L.D. et al. Factors that influence the prevalence of acaricide resistance and tick-born diseases.

Veterinary Parasitology, Amsterdam, v.125, n.1/2, p.163-181, 2004.

GUGLIELMONE, A.A. Epidemiology of babesiosis and anaplasmosis in South and Central America. Veterinary Parasitology, Amsterdam, v.57, n.1/3, p.109-119, 1995.

\section{INSTITUTO BRASILEIRO DE GEOGRAFIA E} ESTATÍSTICA. Produção da pecuária municipal. Rio de Janeiro, 2004. Disponível em: <http://Www.ibge. br/home/, estatistica/economia/ppm/2004/ppm2004.pdf $>$. Acesso em: 23 maio 2006 .

\section{INSTITUTO INTERAMERICANO DE COOPERACION} PARA LA AGRICULTURA. Técnicas para el diagnóstico de babesiosis y anaplasmosis bovinas. San José, 1987. $79 \mathrm{p}$.

JONSSON, N.N.; BOCK, R.E.; JORGENSEN, W.K. Productivity and health effects of anaplasmosis and babesiosis on Bos indicus cattle and their crosses, and the effects of differing intensity of tick control in Australia. Veterinary Parasitology, Amsterdam, v.155, p.1-9, 2008.

KUTTLER, K.L. World-wide impact of babesiosis. In: RISTIC, M. Babesiosis of domestic animals and man. Florida: CRC, 1988. p.1-28. 
LIMA, W.S.; RIBEIRO, M.F.B.; GUIMARÃES, M.P. Seasonal variation of Boophilus microplus (Canestrini, 1887) (Acari:Ixodidae) in cattle in Minas Gerais State, Brazil. Tropical Animal Health and Production, Edinburgh, v.32, n.6, p.375-380, 2000.

MADRUGA, C.R. et al. Desenvolvimento de uma prova de imunoadsorção enzimática para detecção de anticorpos contra Babesia bovis. Pesquisa Veterinária Brasileira, Rio de Janeiro, v.20, n.4, p.167-170, 2000.

MAHONEY, D.F.; ROSS, D.R. Epizootiological factors in the control of bovine babesiosis. Australian Veterinary Journal, Melbourne, v.48, p.292-298, 1972.

PATARROYO, J.H. et al. Epidemiologia das babesioses bovinas no estado de Minas Gerais: I., prevalência de anticorpos fluorescentes na zona da Mata. Arquivo Brasileiro de Medicina Veterinária e Zootecnia, Belo Horizonte, v.39, n.3, p.423-429, 1987.

SANTANA, A.P. et al. Dinâmica da infecção natural por Babesia bigemina em bezerros a partir do nascimento detectado pela reação em cadeia da polimerase. Ciência Animal Brasileira, Goiânia, v.9, n.3, p.721-730, 2008.

SANTOS, H.Q.; LINHARES, G.F.C.; MADRUGA, C.R. Estudo da prevalência de anticorpos anti-Babesia bovis e anti-Babesia bigemina em bovinos de leite da microrregião de Goiânia determinada pelos testes de imunofluorescência indireta e Elisa. Ciência Animal Brasileira, Goiânia, v.2, n.2, p.133-137, 2001.

SOARES, C.O. et al. Seroprevalence of Babesia bovis in cattle in the Norte Fluminense region. Pesquisa Veterinária Brasileira, Rio de Janeiro, v.20, n.2, p.75-79, 2000.

SOLORIO-RIVERA, J.L. et al. Management factors associated with Babesia bovis seroprevalence in cattle from eastern Yucatán, Mexico. Preventive Veterinary Medicine, Berlin, v.40, p.261-269, 1999.

VILORIA, M.I.V.; SALCEDO, J.H.P. Patofisiologia da infecção por Babesia bovis. Revista Brasileira de Parasitologia Veterinária, São Paulo, v.13, n.1, p.12-16, 2004. Suplemento. 